\title{
Simultaneous Cultivation of Spirulina platensis and the Toxigenic Cyanobacteria Microcystis aeruginosa
}

Jorge Alberto Vieira Costa*, Michele Greque de Morais, Francieli Dalcanton, Carolina da Cruz Reichert, and Andrei José Durante

Laboratório de Engenharia Bioquímica, Departamento de Química, Fundação Universidade Federal do Rio Grande, Caixa Postal 474, CEP 96201-900, Rio Grande, RS, Brazil. Fax: +55-53-32338745. E-mail: dqmjorge@furg.br

* Author for correspondence and reprint requests

Z. Naturforsch. 61c, 105-110 (2006); received July 6, 2005

Mangueira Lagoon, located in the extreme south of Brazil, has water with physicochemical characteristics such as alkaline $\mathrm{pH}$ and carbonate levels propitious for the growth of the cyanobacterium Spirulina platensis. Previously published studies have shown that Mangueira Lagoon water supplemented with small quantities of carbon and nitrogen is suitable for $S$. platensis cultivation and can significantly reduce production costs. We studied mixed cultures of Spirulina platensis and the toxic cyanobacterium Microcystis aeruginosa using a $2^{3}$ factorial design in which the three factors were the initial biomass concentration of $S$. platensis and M. aeruginosa and the type of culture medium (100\% Zarrouk's medium or $80 \%$ Mangueira Lagoon water plus $20 \%$ Zarrouk's medium). The highest S. platensis maximum specific growth rate $\left(\mu_{\max }\right)$ occurred in the culture with the highest $M$. aeruginosa biomass concentration and when undiluted culture medium was used $\left(\mu_{\max }=0.283 \mathrm{~d}^{-1}\right)$. The highest $M$. aeruginosa specific death rate $(k)$ was obtained in the presence of $S$. platensis $\left(k=0.555 \mathrm{~d}^{-1}\right)$ and was independent of the initial $M$. aeruginosa biomass concentration and culture medium, demonstrating that $S$. platensis cultures are not susceptible to contamination by $M$. aeruginosa. The culture medium had no significant influence $(p>0.05)$ on $S$. platensis $\mu_{\max }$ values, indicating that production costs could be reduced by using a medium consisting of $80 \%$ Mangueira Lagoon water plus 20\% Zarrouk's medium.

Key words: Cyanobacteria, Microcystis aeruginosa, Spirulina platensis

\section{Introduction}

The filamentous cyanobacterium Spirulina platensis is identified mainly by the helical arrangement of its multicellular cylindrical trichomes (Vonshak, 1997) which appear microscopically as greenish filaments up to $1 \mathrm{~mm}$ in length (Vymazal, $1995)$ and 1 to $12 \mu \mathrm{m}$ in diameter with a free moving axis and no heterocysts (Richmond, 1990). This cyanobacterium inhabits soils, sands, swamps, alkaline lakes and brackish waters, marinas and docks where it uses photosynthesis to transform water and nutrients into biomass and oxygen.

Proteins make up 64 to $74 \%$ of the total biomass of S. platensis and, according to Vonshak et al. (1983), the lipid content varies from 6 to $13 \%$ and the carbohydrate content from 12 to $20 \%$, which means that Spirulina biomass is highly nutritional and can be used as a food supplement for humans and animals and as a source of fine chemicals. Due to its ecological, nutritional and economic importance Spirulina has been the subject of intensive biotechnological studies. Reports showing that this cyanobacterium is an estuarine or marine species that can be produced on a commercial scale in temperate latitudes (Costa et al., 2000) and several companies have industrialized $S$. platensis production because its cultivation requirements are simple, industrial residues can serve as feedstock and its growth rate is high. Clinical studies suggest that consumption of $S$. platensis has beneficial therapeutic effects on humans, including reduced serum cholesterol, hyperlipodemia and obesity, increased intestinal lactobacilli, improved immune response, protection against some cancers, and a reduction in the effects of exposure to radiation (Costa et al., 2004).

The cosmopolitan freshwater colonial cyanobacteria Microcystis aeruginosa (Chroococcales, Chroococcaceae) principally inhabits temperate and tropical latitudes but has been reported from some subtropical areas. Cyanobacterial blooms of toxic Microcystis species pose serious ecological problems for animal and human health, M. aeruginosa is known to cause bad odors in lakes and 
reservoirs and to produce hepatotoxicity in animals and humans (Fleming et al., 2002). Metabolically, $M$. aeruginosa is unable to fix atmospheric nitrogen and thus needs assimilable forms of nitrogen such as $\mathrm{NH}_{4}{ }^{+}$or $\mathrm{NO}_{3}{ }^{-}$for growth (Yunes and Leon, 2001; Falconer, 1999; Falconer and Humpage, 1996; Bell and Codd, 1994; Carmichael, 1994; Gorham and Carmichael, 1980).

Although the commercial cultivation of cyanobacteria is basically quite a simple industrial process the fact that the growth medium for these organisms is complex makes industrial scale production difficult and costly and has led to the search for new, lower cost, nutrient sources. Previous studies (Costa et al., 2003, 2002) have demonstrated that water from Mangueira Lagoon $\left(33^{\circ} 30^{\prime} \mathrm{S} ; 53^{\circ} 08^{\prime} \mathrm{W}\right)$, situated in the southern Brazilian state of Rio Grande do Sul between Mirim Lagoon and the Atlantic Ocean, has favorable physico-chemical characteristics for the cultivation of $S$. platensis in that it has the alkaline $\mathrm{pH}$ and high carbonate and bicarbonate content necessary for the growth of this cyanobacterium.

One problem that may arise with the use of natural unprocessed lake water for the cultivation of $S$. platensis is that cultures could be subject to contamination with toxigenic $M$. aeruginosa. The aim of the work described in this paper was to evaluate the growth of $M$. aeruginosa in artificially-contaminated $S$. platensis cultures and to ascertain whether or not the growth of toxigenic algae could pose a problem for the cultivation of $S$. platensis.

\section{Material and Methods}

\section{Microorganisms and culture medium}

The cyanobacteria Spirulina platensis strain LEB-52 (Costa et al., 2000) and Microcystis aeruginosa strain RST 9501 (Yunes and Leon, 2001) were used in this study. The toxic Microcystis aeruginosa strain RST 9501 was supplied by the "Unidade de Pesquisa em Cianobactéria" of Fundação Universidade Federal do Rio Grande. Its toxicity and toxin content have been reported by Yunes et al. (1996) and Matthiensen et al. (2000). For maintenance and inoculum preparation we used Zarrouk's medium (Zarrouk, 1966) for S. platensis and BGN/2 medium (Rippka et al., 1979) for $M$. aeruginosa. The production runs were carried out using undiluted Zarrouk's medium (medium A), Mangueira Lagoon water supplemented with $20 \%$ (v/v) Zarrouk's medium (medium B) and Man- gueira Lagoon water supplemented with $60 \%$ (v/v) Zarrouk's medium (medium C). Mangueira Lagoon is situated at $33^{\circ} 30^{\prime} \mathrm{S} ; 53^{\circ} 08^{\prime} \mathrm{W}$ in the southern Brazilian state of Rio Grande do Sul between Mirim Lagoon and the Atlantic Ocean. All reagents were at least of analytical quality.

\section{Cultivation}

The cyanobacteria were cultivated in $0.25 \mathrm{~L}$ closed bioreactors using a $0.2 \mathrm{~L}$ working-volume and aerated at a rate of $20 \mathrm{~L} \mathrm{~h}^{-1}$ using diaphragm pumps. Light was provided using $20 \mathrm{~W}$ daylighttype fluorescent lamps (General Electric) at an illuminance of 1200 Lux and a $12 \mathrm{~h}: 12 \mathrm{~h}$ light:dark photoperiod (Tanticharoen et al., 1994). The bioreactors were maintained at a constant $30{ }^{\circ} \mathrm{C}$ in a growth chamber (Sarada et al., 1999; Zhang et al., 1999) and the total growth time was $623 \mathrm{~h}$.

The bioreactor experiments were carried out, in duplicate, as separate runs according to a complete $2^{3}$ factorial design where the initial biomass was 0 or $0.1 \mathrm{~g} \mathrm{~L}^{-1}$ for $S$. platensis and 0.01 or $0.03 \mathrm{~g} \mathrm{~L}^{-1}$ for $M$. aeruginosa (Table I). Two additional monoculture $S$. platensis standard runs were carried out with an initial biomass concentration of $0.1 \mathrm{~g}$ $\mathrm{L}^{-1}$, one employing medium $\mathrm{A}$ and the other medium B, along with two mixed-species standard runs in medium C using $0.1 \mathrm{~g} \mathrm{~L}^{-1}$ initial S. platensis biomass concentration and a $M$. aeruginosa initial biomass concentration of $0.2 \mathrm{~g} \mathrm{~L}^{-1}$.

Table I. Initial and final S. platensis and M. aeruginosa biomass values during growth for $623 \mathrm{~h}$ in undiluted Zarrouk's medium (medium A) and in Mangueira Lagoon water supplemented with $20 \%$ (v/v) Zarrouk's medium (medium B). Each run was duplicated and the final biomass values represent the arithmetic mean of the two runs.

\begin{tabular}{ccc}
\hline & \multicolumn{2}{c}{ Initial biomass $\left(\mathrm{g} \mathrm{L}^{-1}\right)$} \\
\cline { 2 - 3 } Run & S. platensis & M. aeruginosa \\
\hline Medium A & & \\
1 & 0.00 & 0.01 \\
2 & 0.10 & 0.01 \\
3 & 0.00 & 0.03 \\
4 & 0.10 & 0.03 \\
Medium B & & \\
5 & 0.00 & 0.01 \\
6 & 0.10 & 0.01 \\
7 & 0.00 & 0.03 \\
8 & 0.10 & 0.03 \\
\hline
\end{tabular}


In pre-run trials samples were collected, aseptically, every $48 \mathrm{~h}$ and the total number of $S$. platensis filaments or $M$. aeruginosa cells calculated using a S50 Sedgewick-Rafter cell and phasecontrast microscopy at 100x magnification and the data used to construct calibration curves (data not shown) relating dry biomass weight to cell or filament numbers for $M$. aeruginosa or S. platensis, respectively. For each experimental run samples were collected every $48 \mathrm{~h}$ and the dry biomass values used to calculate the biomass doubling time $\left(t_{\mathrm{d}}\right)$ and maximum specific growth rate $\left(\mu_{\max }\right)$ for $S$. platensis and the death time $\left(D_{\mathrm{t}}=\right.$ time needed for the $M$. aeruginosa biomass to drop by $50 \%$ ) and specific death rate $(k)$ for $M$. aeruginosa, $\mu_{\max }$ and $k$ are calculated by exponential regression of the ascending and descending logarithmic sections of the growth curves. Death rate was calculated as $t_{\mathrm{d}}=\ln 2 / \mu_{\max }$ and death time as $D_{\mathrm{t}}=\ln 2 / k$.

\section{Results and Discussion}

The $t_{\mathrm{d}}$ and $\mu_{\max }$ values for Spirulina platensis and $k$ and $D_{\mathrm{t}}$ for Microcystis aeruginosa are shown in Table II. The mean $\mu_{\max }$ value for $S$. platensis was $(0.245 \pm 0.029) \mathrm{d}^{-1}$ but in mixed cultures $\mu_{\max }$ varied from $(0.283 \pm 0.030) \mathrm{d}^{-1}$ in medium $A$ inoculated with $0.03 \mathrm{~g} \mathrm{~L}^{-1}$ of M. aeruginosa to $(0.214$ $\pm 0.007) \mathrm{d}^{-1}$ in medium $\mathrm{B}$ inoculated with $0.01 \mathrm{~g}$ $\mathrm{L}^{-1}$ of $M$. aeruginosa, while the lowest $S$. platensis $t_{\mathrm{d}}$ values occurred in runs 4 and 8 in which the initial $M$. aeruginosa biomass concentration was highest $\left(0.03 \mathrm{~g} \mathrm{~L}^{-1}\right)$ (Table II).

The $S$. platensis monoculture standard runs with medium A gave $\mu_{\max }=0.153 \mathrm{~d}^{-1}$ and $0.173 \mathrm{~d}^{-1}$ for medium $\mathrm{B}$, these values were lower than the lowest $\mu_{\max }$ values occurring in the mixed cultures (Table II). It thus seems that the presence of $M$. aeruginosa did not reduce the $S$. platensis $\mu_{\max }$ value but, on the contrary, in some cases increased it.

Alkaline medium with $\mathrm{pH} 8.5$ to 11 is normally used to cultivate Spirulina species and this generally prevents the growth of algae, bacteria, fungi and yeasts, additional bacteriostatic or bactericidal protection is supplied by compounds such as sterols which represent up to $1.5 \% \mathrm{w} / \mathrm{w}$ of the nonpolar lipid fraction of Spirulina species (Parada et al., 1998).

The highest $M$. aeruginosa specific death rate was $k=(0.555 \pm 0.014) \mathrm{d}^{-1}$ for run $2, S$. platensis was present in run. Taken in conjunction with the results described above, the data suggests that not only $S$. platensis is not susceptible to contamination with $M$. aeruginosa but that $S$. platensis can inhibit the growth of $M$. aeruginosa during the first few hours of cultivation. The $D_{\mathrm{t}}$ value represents the time taken for the biomass concentration to drop by $50 \%$, and it can be seen from Table II that there are large differences between the $D_{\mathrm{t}}$ values for $M$. aeruginosa grown in monoculture or in the presence of $S$. platensis, with the mean $M$. aeruginosa monoculture $D_{\mathrm{t}}$ value being $(3.40 \pm 0.24) \mathrm{d}$ as compared to $(2.04 \pm 0.21) \mathrm{d}$ when grown in mixed culture with $S$. platensis.

Our data supports the work of Goodman et al. (2000) who analyzed 62 products enriched with $S$. platensis but found no evidence of microcystin (the toxin produced by Microcystis aeruginosa), although this toxin has been found in products enriched with other cyanobacteria and/or microalgae.

The growth curves for the $S$. platensis and $M$. aeruginosa monocultures growing in medium $\mathrm{B}$ (Mangueira Lagoon water supplemented with $20 \%$ Zarrouk's medium) are shown in Fig. 1, from which it can be seen that the M. aeruginosa biomass remained constant during the first $100 \mathrm{~h}$ of

\begin{tabular}{ccccc}
\hline & \multicolumn{2}{c}{ S. platensis } & \multicolumn{2}{c}{ M. aeruginosa } \\
\cline { 2 - 5 } Run & $t_{\mathrm{d}}[\mathrm{d}]$ & $\mu_{\max }\left[\mathrm{d}^{-1}\right]$ & $D_{\mathrm{t}}[\mathrm{d}]$ & $k\left[\mathrm{~d}^{-1}\right]$ \\
\hline 1 & - & - & $3.25 \pm 0.42$ & $0.202 \pm 0.045$ \\
2 & $3.22 \pm 0.11$ & $0.214 \pm 0.007$ & $1.31 \pm 0.04$ & $0.525 \pm 0.017$ \\
3 & - & - & $3.62 \pm 0.24$ & $0.191 \pm 0.012$ \\
4 & $2.79 \pm 0.14$ & $0.248 \pm 0.012$ & $3.03 \pm 0.56$ & $0.312 \pm 0.015$ \\
5 & - & - & $4.32 \pm 0.26$ & $0.160 \pm 0.009$ \\
6 & $2.94 \pm 0.04$ & $0.235 \pm 0.002$ & $2.61 \pm 0.24$ & $0.265 \pm 0.024$ \\
7 & - & - & $2.30 \pm 0.07$ & $0.299 \pm 0.010$ \\
8 & $2.46 \pm 0.26$ & $0.283 \pm 0.030$ & $1.24 \pm 0.03$ & $0.555 \pm 0.014$ \\
\hline
\end{tabular}

Table II. Biomass doubling times $\left(t_{\mathrm{d}}\right)$ and maximum specific growth rates $\left(\mu_{\max }\right)$ for $S$. platensis and death times $\left(D_{\mathrm{t}}\right)$ and specific death rates $(k)$ for $M$. aeruginosa in a $2^{3}$ factorial design experiment. Values shown are means \pm standard deviation. 


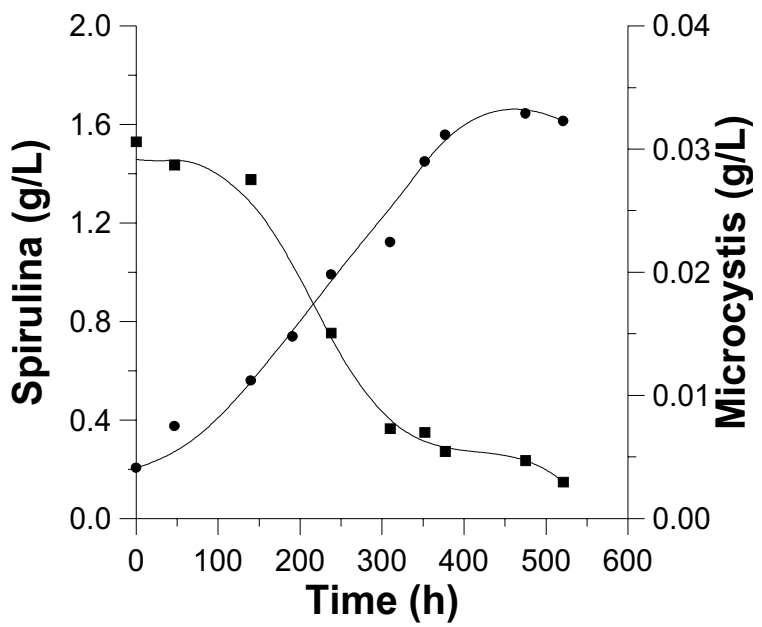

Fig. 1. Growth curves (biomass versus time) of pure cul-

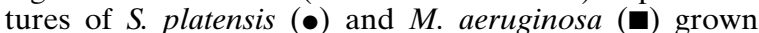
separately in $20 \%$ Zarrouk's medium plus $80 \%$ Mangueira Lagoon water. Initial biomass was $0.1 \mathrm{~g} \mathrm{~L}^{-1}$ for $S$. platensis and $0.03 \mathrm{~g} \mathrm{~L}^{-1}$ for $M$. aeruginosa.

cultivation but by $300 \mathrm{~h}$ had declined to almost zero and remained at this level until the end of the experiment.

When growing together both $S$. platensis and $M$. aeruginosa showed similar tendencies in runs 2 and 4 in that the growth of $S$. platensis seemed to

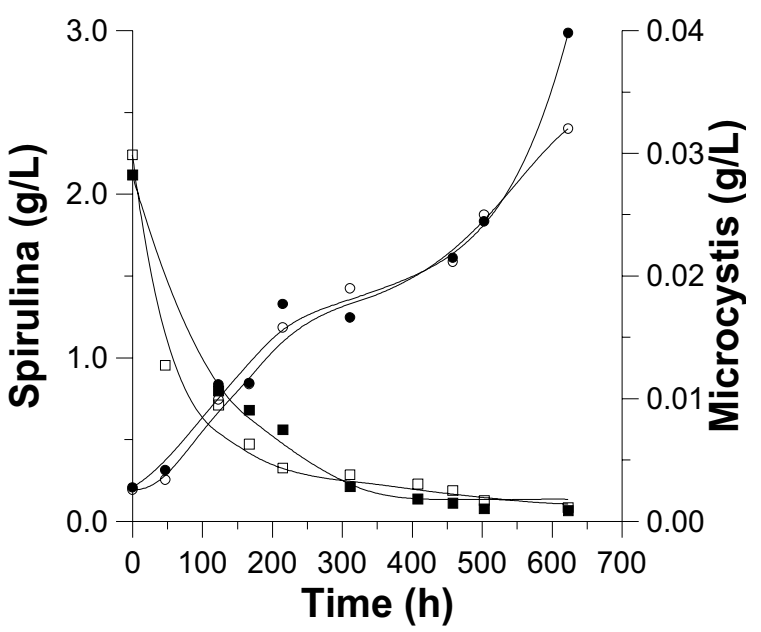

Fig. 2. Growth curves (biomass versus time) for S. platensis and $M$. aeruginosa growing simultaneously in $20 \%$ Zarrouk's medium plus $80 \%$ Mangueira Lagoon water. Results for run 2 with an initial biomass of $0.1 \mathrm{~g} \mathrm{~L}^{-1}$ for $S$. platensis $(\bullet)$ and $0.01 \mathrm{~g} \mathrm{~L}^{-1}$ for $M$. aeruginosa $(\mathbf{\square})$ and run 4 with an initial biomass of $0.1 \mathrm{~g} \mathrm{~L}^{-1}$ for $S$. platensis (○) and $0.03 \mathrm{~g} \mathrm{~L}^{-1}$ for M. aeruginosa ( $\square$ ).
Table III. Maximum specific growth rate $\left(\mu_{\max }, \mathrm{d}^{-1}\right)$ effects, errors and significance values $(p)$ obtained in a complete $2^{2}$ factorial analysis experiment with $S$. platensis.

\begin{tabular}{cccc}
\hline Factor & Effect $\left[\mathrm{d}^{-1}\right]$ & Error & $p$ \\
\hline $\mathrm{X}_{1}$ & 0.040 & 0.023 & 0.145 \\
$\mathrm{X}_{2}$ & 0.027 & 0.023 & 0.294 \\
$\mathrm{X}_{1} * \mathrm{X}_{2}$ & 0.007 & 0.023 & 0.787 \\
\hline
\end{tabular}

$\mathrm{X}_{1}$, initial $M$. aeruginosa biomass concentration; $\mathrm{X}_{2}$, culture medium.

be unaffected by the initial biomass concentration of $M$. aeruginosa (Fig. 2). The curves show that shortly after inoculation there was a sharp decrease in $M$. aeruginosa biomass which reached close to zero at $300 \mathrm{~h}$ and remained at this level until the end of the experiments, while for S. platensis a small lag phase lasting until about $40 \mathrm{~h}$ after inoculation followed by exponential growth. Comparing the behavior of M. aeruginosa in monoculture (Fig. 1) and mixed culture (Fig. 2) it can be seen that this toxigenic cyanobacterium shows a lag phase in monoculture but not when cultivated simultaneously with $S$. platensis.

The $S$. platensis $\mu_{\max }$ values obtained in the runs involving this cyanobacteria were analyzed as a $2^{2}$ factorial experiment, the results showing that neither the biomass concentration of $M$. aeruginosa nor the type of medium (i.e. medium $\mathrm{A}$ or $\mathrm{B}$, medium $C$ being excluded from this analysis) had any statistically significant $(p>0.05)$ effect on the $S$. platensis $\mu_{\max }$ values (Table III).

Our results indicate that Mangueira Lagoon water supplemented with $20 \%$ Zarrouk's medium (medium B) has suitable physico-chemical characteristics (e.g. alkalinity, carbonate content and micronutrient level) for the growth of $S$. platensis, supporting the view (Costa et al., 2003, 2002) that the addition of small quantities of carbon and nitrogen sources to Mangueira Lagoon water is enough to ensure that this water can be used for the cultivation of $S$. platensis and can thus significantly reduce production costs for this cyanobacterium.

The data in Table IV was produced using not only the results shown in Table II but also the data from the two standard central point values with M. aeruginosa $\left(0.02 \mathrm{~g} \mathrm{~L}^{-1}\right)$ and $S$. platensis $(0.1 \mathrm{~g}$ $\mathrm{L}^{-1}$ ) in mixed-culture runs using medium $\mathrm{C}$. This analysis shows that the presence of $S$. platensis had a significant effect $(p=0.010)$ in increasing the 
Table IV. Specific death rate $\left(k, \mathrm{~d}^{-1}\right)$ effects, errors and significance values $(p)$ obtained in a complete $2^{3}$ factorial analysis experiment with $M$. aeruginosa in simultaneous culture with $S$. platensis.

\begin{tabular}{cccl}
\hline Factor & Effect $\left[\mathrm{d}^{-1}\right]$ & Error & \multicolumn{1}{c}{$p$} \\
\hline $\mathrm{X}_{1}$ & 0.153 & 0.048 & $0.010^{*}$ \\
$\mathrm{X}_{2}$ & 0.024 & 0.048 & 0.638 \\
$\mathrm{X}_{3}$ & -0.137 & 0.048 & $0.022^{*}$ \\
$\mathrm{X}_{1} * \mathrm{X}_{2}$ & 0.007 & 0.048 & 0.881 \\
$\mathrm{X}_{1} * \mathrm{X}_{3}$ & 0.080 & 0.048 & 0.136 \\
$\mathrm{X}_{2} * \mathrm{X}_{3}$ & -0.121 & 0.048 & $0.036^{*}$ \\
\hline
\end{tabular}

$\mathrm{X}_{1}$, initial S. platensis biomass concentration; $\mathrm{X}_{2}$, initial $M$. aeruginosa biomass concentration; $\mathrm{X}_{3}$, culture medium.

* Statistically significant at $p \geq 0.05$.

specific death rate $(k)$ of $M$. aeruginosa. The interaction among initial $M$. aeruginosa biomass concentration and medium composition had a significant effect $(p=0.036)$ in decreasing the specific death rate $(k)$ of $M$. aeruginosa and the Mangueira Lagoon water supplemented with $20 \%(\mathrm{v} / \mathrm{v})$ Zarrouk's medium had a significant effect $(p=$ $0.022)$ in increasing the specific death rate $(k)$ of $M$. aeruginosa (Table IV). Our results show that $S$. platensis accelerated the decline in $M$. aeruginosa biomass not only in medium B but also in medium $\mathrm{C}$.

Bell S. G. and Codd G. A. (1994), Cyanobacterial toxins and human health. Med. Microbial. 5, 256-264.

Carmichael W. W. (1994), The toxins of cyanobacteria. Sci. Am. 270, 64-70.

Costa J. A. V., Linde G. A., Atala D. I. P., Mibieli G. M., and Krüger R. T. (2000), Modelling of growth conditions for cyanobacterium Spirulina platensis in microcosms. World J. Microb. Biot. 16, 15-18.

Costa J. A. V., Colla L. M., Duarte P., Kabke K., and Weber A. (2002), Modelling of Spirulina platensis growth in fresh water using response surface methodology. World J. Microb. Biot. 7, 603-607.

Costa J. A. V., Colla L. M., and Duarte P. (2003), Spirulina platensis growth in open raceway ponds using fresh water supplemented with carbon, nitrogen and metal ion. Z. Naturforsch. 58c, 76-80.

Costa J. A. V., Colla L. M., and Filho P. F. D. (2004), Improving Spirulina platensis biomass yield using a fedbatch process. Bioresource Technol. 92, 237-241.

Falconer I. R. (1999), An overview of problems caused by toxic blue-green algae (cyanobacteria) in drinking and recreation water. Environ. Toxicol. 14, 5-12.

\section{Conclusions}

Neither cultures of Spirulina platensis were not susceptible to contamination by Microcystis aeruginosa nor did the initial concentration of this toxigenic microalgae have any significant negative effect on the maximum specific growth rate $\left(\mu_{\max }\right)$ of $S$. platensis, although it is possible that the $\mu_{\max }$ value for $S$. platensis increased in mixed cultures with $M$. aeruginosa. The presence of $S$. platensis, type of culture medium and the interaction between the initial biomass concentration of $M$. aeruginosa and culture medium all had a significant influence in the specific death rate $(k)$ of $M$. aeruginosa. There was no significant difference between the different culture media [undiluted Zarrouk's medium or Mangueira Lagoon water supplemented with $60 \%$ or $20 \%$ (v/v) of Zarrouk's medium], indicating that undiluted Zarrouk's medium could be replaced by Mangueira Lagoon water supplemented with $20 \%$ (v/v) of Zarrouk's medium thereby considerably reducing $S$. platensis production costs.

\section{Acknowledgements}

The authors are greatful to Dr. João Sarkis Yunes and Unidade de Pesquisa em Cianobactérias people for the cooperation during the experimental procedure.

Falconer I. R. and Humpage A. R. (1996), Potential impact on human health of toxic cyanobacteria. Phycologia 35, 6-11.

Fleming L. E., Rivero C., Burns J., Williams C., Bean J., Shea K. A., and Stinn J. (2002), Blue green algal (cyanobacterial) toxins, surface drinking water, and liver cancer in Florida. Harmful Algae 1, 157-168.

Goodman T. K., Lawrence J. F., and Morrisey M. (2000), Risk Assessment of microcystins in blue-green algal health food products. Mycotoxins and phycotoxins in perspective at the turn of the millennium. Proceedings of the $\mathrm{X}^{\text {th }}$ International IUPAC symposium on Mycotoxins and Phycotoxins. Guarujá (Brazil), pp. 549-556.

Gorham P. R. and Carmichael W. W. (1980), Hazards of freshwater blue-green (cyanobacteria). In: Algae and Human Affairs (Lembi C. A., ed.). Cambridge University Press, Cambridge, England.

Matthiensen A., Beattie K. A., Yunes J. S., Kaya K., and Cood G. A. (2000), [D-leu] microcystin-LR, from the cyanobacterium Microcystis RST 9501 and from a Microcystis bloom in the Patos Lagoon Estuary, Brazil. Phytochemistry 55, 383-387. 
Parada J. I., Caire G. Z., Mulé M. C. Z., and Cano M. M. S. (1998), Lactic acid bacteria growth promoters from Spirulina platensis. Int. J. Food Microbiol. 45, $225-228$.

Richmond A. (1990), Handbook of Microalgal Mass Culture. CRC Press, Boca Raton, USA.

Rippka J. E., Derruelles J., Waterbury J. B., Herdeman M., and Satiner R. Y. (1979), Generic assignments, stain histories, and properties of pure culture of cyanobacterial. J. Gen. Appl. Microbiol. 111, 1-6.

Sarada R., Pillai G., and Ravishankar G. A. (1999), Phycocyanin from Spirulina sp.: influence of processing of biomass on phycocyanin yield, analysis of efficacy of extraction methods and stability studies on phycocyanin. Process Biochem. 34, 795-801.

Tanticharoen M., Reungjitchachawali M., Boonag B., Vonktaveesuk P., Vonshak A., and Cohen Z. (1994), Optimization of $\gamma$-linolenic acid (GLA) production in Spirulina platensis. J. Appl. Phycol. 6, 295-300.

Vonshak A. (1997), Spirulina platensis (Arthrospira): Physiology, Cell-biology and Biotechnology. Taylor \& Francis, London, UK.

Vonshak A., Boussiba S., Abeliovich A., and Richmond A. (1983), Production of Spirulina biomass: maintenance of monoalgal culture outdoors. Biotechnol. Bioeng. 25, 341-349.
Vymazal J. (1995), Algae and Element Cycling in Wetlands. Ed. Lewis Publishers, Boca Raton, Florida, USA.

Yunes J. S. and Leon L. (2001), First report of a microcystin-containing bloom of the cyanobacterium Microcystis aeruginosa in the La Plata River, South America. Environ. Toxicol. 16, 110-112.

Yunes J. S., Salomon P. S., Matthiensen A., Beattie K. A., Ragget S. L., and Codd G. A. (1996), Toxic blooms of cyanobacteria in the Patos Lagoon Estuary, southern Brazil. J. Aquatic. Ecosyst. Health. 5, 223229.

Zarrouk C. (1966), Contribution à l'étude d'une cyanophycée. Influence de divers facteurs physiques et chimiques sur la croissance et la photosynthèse de Spirulina maxima. Ph. D. Thesis, Université de Paris.

Zhang X. W., Zhang Y. M., and Chen F. (1999), Application of mathematical models to the determination optimal glucose concentration and light intensity for mixotrophic culture of Spirulina platensis. Process Biochem. 34, 477-481. 